\title{
Quantitative estimation of aortic valve calcification in multislice computed tomography in predicting the development of paravalvular leaks following transcatheter aortic valve replacement
}

\author{
Małgorzata Ryś $\tilde{s}^{1}$, Tomasz Hryniewiecki ${ }^{1}$, llona Michałowska ${ }^{2}$, Patrycjusz Stokłosa ${ }^{1}$, \\ Monika Różewicz-Juraszek ${ }^{1}$, Zbigniew Chmielak ${ }^{3}$, Maciej Dąbrowski ${ }^{3}$, Kryspin Mirota ${ }^{4}$, Piotr Szymański ${ }^{1}$ \\ ${ }^{1}$ Department of Valvular Heart Disease, Institute of Cardiology, Warsaw, Poland \\ ${ }^{2}$ Department of Radiology, Institute of Cardiology, Warsaw, Poland \\ ${ }^{3}$ Department of Interventional Cardiology and Angiology, Institute of Cardiology, Warsaw, Poland \\ ${ }^{4}$ Faculty of Mechanical Engineering and Computer Science, University of Bielsko-Biala, Bielsko-Biala, Poland
}

Adv Interv Cardiol 2018; 14, 1 (51): 85-89

DOI: https://doi.org/10.5114/aic.2018.74359

\begin{abstract}
A bstract
Introduction: Transcatheter aortic valve implantation (TAVI) improves prognosis in patients disqualified from surgical valve replacement. Calcifications of the aortic complex can lead to deformation of the prosthesis, resulting in paravalvular leaks (PVL).

Aim: To evaluate the predictive value of quantitative estimation of volume/weight and geometric distribution of calcifications in multislice computed tomography, for the development of PVL.

Material and methods: This was a retrospective, case-control study on patients with a CoreValve aortic prosthesis. The study group consisted of 20 patients with confirmed significant PVL after TAVI. The control group consisted of 20 patients without significant PVL, matched according to valve type and clinical characteristics. The size spatial distribution and shape of calcifications were measured.

Results: The average age of patients was 79.9 years (60\% women). Cases and controls did not differ in their clinical characteristics. The size of the aortic annulus was significantly larger in cases vs. controls $(23.4 \pm 1.6 \mathrm{vs.} 22 \pm 1.4 \mathrm{~mm}, p=0.01)$. Volume, area and curvature of calcifications were greater in cases vs controls (1.09 $\pm 0.56 \mathrm{vs} .0 .59 \pm 0.41 \mathrm{~cm}^{3}, p=0.011 ; 15.26 \pm 5.46 \mathrm{vs} .9 .50 \pm 5.29 \mathrm{~cm}^{2}$, $p=0.008 ; 1.76 \pm 0.07$ vs. $1.68 \pm 0.13 \mathrm{~cm}^{3}, p=0.037$ ). In multivariate analysis, adjusted for aortic annulus size, the area of aortic valve calcifications independently predicted paravalvular regurgitation ( $\mathrm{OR}=1.41,95 \% \mathrm{Cl}: 0.09-1.92, p<0.009)$.

Conclusions: Morphometric analysis of aortic valve calcifications predicted the risk of paravalvular leak following TAVI irrespectively of patients' clinical characteristics.
\end{abstract}

Key words: aortic stenosis, transcatheter aortic valve implantation, aortic regurgitation.

\section{Introduction}

Transcatheter aortic valve implantation (TAVI) improves prognosis in patients who are disqualified from surgical replacement of the valve and also high-risk patients whose transcutaneous interventions are an alternative to classical surgery [1-3]. The procedure of implantation involves active and passive expansion of the prosthesis in the aortic valve. The degree and nature of aortic root calcifications is one of the factors affecting the outcome of the intervention [4]. Severe, asymmetric calcifications can lead to deformation of the prosthesis, resulting in paravalvular leaks in a few to dozens or so percent of patients $[5,6]$. The severity of calcification of the aortic complex seems to be related also to the risk of its periprocedural rupture [7]. Paravalvular leaks may also be caused by valve dislocation and undersizing of the prosthesis [8, 9]. Aortic root calcification was usually assessed either qualitatively or semi-quantitatively, based on subjective scales of echocardiographic criteria and/or Agatston scoring. In most cases geometric distribution of calcifications was not assessed or assessed 
only semi-quantitatively [10-12]. The geometry of calcifications however seems to be crucial to the success of the intervention, based on the experience gathered in patients with bicuspid aortic valves [13, 14].

\section{Aim}

The aim of the current study was to evaluate the possibility of using the quantitative estimation of volume/ weight and geometric distribution of calcification in multi-slice computed tomography (MSCT) in predicting the development of paravalvular leaks following TAVI.

\section{Material and methods}

\section{Study group}

This was a case-control study on a retrospectively selected group of patients with a percutaneously implanted CoreValve aortic prosthesis. The study group consisted of 20 patients with echocardiographically confirmed significant paravalvular leak after TAVI, defined as at least moderate aortic regurgitation. The control group consisted of 20 patients, matched according to their clinical characteristics, without significant paravalvular leak following CoreValve implantation.

\section{Multi-slice computed tomography (MSCT)}

Before TAVI, all patients had had an MSCT examination evaluating the atherosclerotic deposits of the aortic valve. Non-contrast and contrast ECG-gated computed tomography examinations were performed with a dual source scanner (Somatom Definition Flash, Siemens Medical Solutions) with beam collimation of $64 \times 0.6 \mathrm{~mm}$, 128 slices, a gantry rotation time of $280 \mathrm{~ms}$, and tube voltage 100-120 kV depending on the patient's body mass. The scan of the heart ranged from the carina to the heart base. The patients did not receive any medicine regardless of the heart rate. Morphometric assessment of calcifications was carried out in three aspects: the volume, area and curvature of calcifications (Figure 1). The starting point for evaluation was the spatial reconstruction of the surface edge using the marching cubes algorithm.
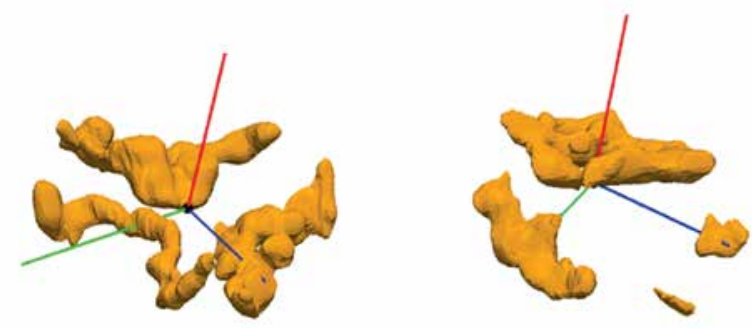

Figure 1. Exemplary reconstruction of aortic valve calcifications. Calcifications located in the aortic valve cusps. There is a variety of calcifications asymmetric calcifications are visible on the right side and symmetrical distribution on the left side

\section{Echocardiography}

The degree of paravalvular leak (which is the criterion for assigning the patient to either the study or control group) was assessed on the basis of a routine transthoracic echocardiographic study performed after TAVI during that hospitalization. The degree of valvular regurgitation was defined according to the Valve Academic Research Consortium (VARC-2) [15]. The residual aortic regurgitation (in the form of paravalvular leak) was classified as: trivial-to-mild ( $\leq 2+$ on a semi-quantitative scale) or moderate-to-severe ( $>2+$ on a semi-quantitative scale).

\section{Statistical analysis}

The groups were characterized by descriptive statistics. Continuous data were expressed as mean \pm standard deviation $( \pm S D$ ), or median and range of values, depending on the distribution, and categorical variables as numbers/percentages (\%). Case and control groups were compared using Student's $t$-test or Mann-Whitney tests in the case of continuous values with normal and skewed distributions respectively, and discrete variables using the $\chi^{2}$ test. Uni- and multivariate logistic regression (adjusting for aortic annulus size) was used to assess the predictive value of aortic valve calcification in the prediction of paravalvular regurgitation. A value of $p<0.05$ was considered to be statistically significant.

\section{Results}

The average age of the studied patients was 79.9 years (62-92 years). Sixty percent of the patients were women ( 24 women, 16 men). Baseline clinical characteristics of cases and controls is presented in Table I. There were no significant differences between groups in the clinical characteristics of patients.

Echocardiographic data in cases and control groups are summarized in Table II. A significant difference was noted in the size of the aortic annulus. The frequency and severity of pre-procedural aortic regurgitation were not significantly different between cases and controls. There were significant differences between cases and controls in the volume (1.09 \pm 0.56 vs. $\left.0.59 \pm 0.41 \mathrm{~cm}^{3}, p=0.011\right)$, area (15.26 \pm 5.46 vs. $\left.9.50 \pm 5.29 \mathrm{~cm}^{2}, p=0.008\right)$, and curvature $\left(1.76 \pm 0.07\right.$ vs. $\left.1.68 \pm 0.13 \mathrm{~cm}^{3}, p=0.037\right)$ of the calcifications (Figure 2). Significant predictors of paravalvular aortic regurgitation following TAVI in univariate analysis are presented in Table III. In multivariate analysis, adjusted for aortic annulus size, the area of aortic valve calcifications independently predicted paravalvular regurgitation $(\mathrm{OR}=1.41,95 \% \mathrm{Cl}$ : 0.09-1.92, $p<0.009)$.

\section{Discussion}

This was a case-control hypothesis generating study that aimed to assess whether quantitative geometric anal- 
Table I. Demographic, clinical and laboratory characteristics of patients

\begin{tabular}{lccc}
\hline Parameter & $\begin{array}{c}\text { Study } \\
\text { group } \\
(n=20)\end{array}$ & $\begin{array}{c}\text { Control } \\
\text { group } \\
(n=20)\end{array}$ & P-value \\
\hline Age [years] & $80.5 \pm 5.6$ & $79.3 \pm 7.21$ & 0.56 \\
\hline Sex (men) & $8(20 \%)$ & $8(20 \%)$ & 1.00 \\
\hline Logistic EuroSCORE (\%) & $22.6 \pm 8.6$ & $20.8 \pm 11.3$ & 0.56 \\
\hline Hypertension & $17(42.5 \%)$ & $15(37.5 \%)$ & 0.42 \\
\hline NYHA functional class III & $19(47.5 \%)$ & $19(47.5 \%)$ & 1.00 \\
\hline NYHA functional class IV & $1(2.5 \%)$ & $1(2.5 \%)$ & 1.00 \\
\hline Creatinine [mg/dl] & $120.5 \pm 72.5$ & $103.8 \pm 30.2$ & 0.34 \\
\hline eGFR [ml/min] & $50.3 \pm 15.9$ & $54.3 \pm 14.3$ & 0.41 \\
\hline Diabetes mellitus & $5(12.5 \%)$ & $7(17.5 \%)$ & 0.54 \\
\hline Coronary artery disease & $16(40 \%)$ & $18(45 \%)$ & 0.65
\end{tabular}

Data are presented as the number (\%) of patients or mean value \pm SD. eGFR - estimated glomerular filtration rate, EuroSCORE - European system for cardiac operative risk evaluation, NYHA - New York Heart Association.

\section{A}

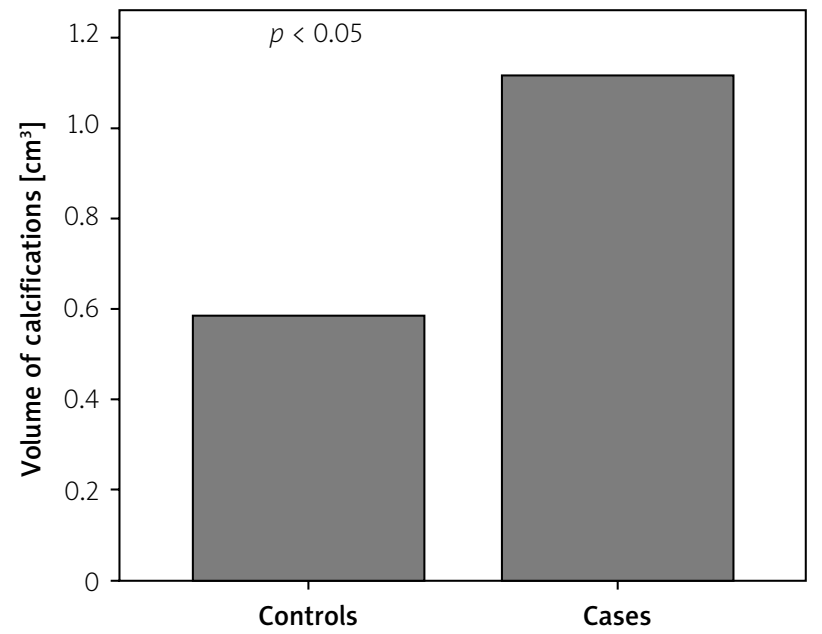

C

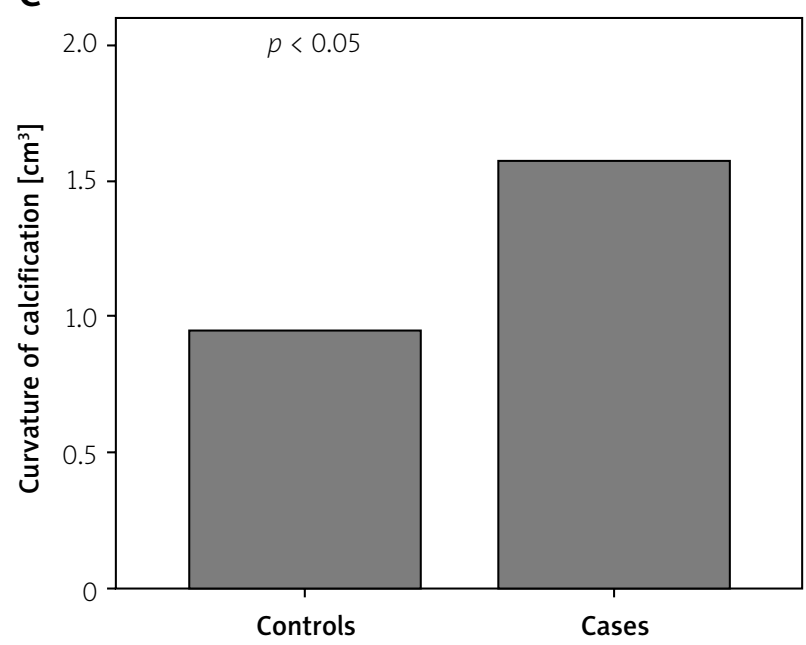

Table II. Comparison of echocardiographic findings in cases and controls

\begin{tabular}{lccc} 
Parameter & $\begin{array}{c}\text { Study } \\
\text { group } \\
(n=20)\end{array}$ & $\begin{array}{c}\text { Control } \\
\text { group } \\
(n=20)\end{array}$ & $P$-value \\
\hline LVDD [mm] & $51.3 \pm 8.6$ & $46.7 \pm 7.4$ & 0.06 \\
\hline IVS [mm] & $15.7 \pm 2.2$ & $15.6 \pm 2.2$ & 0.79 \\
\hline LVOT [mm] & $21.0 \pm 2.3$ & $19.6 \pm 1.8$ & 0.10 \\
\hline Aortic annulus TTE [mm] & $23.4 \pm 1.6$ & $22 \pm 1.4$ & 0.01 \\
\hline Aortic root [mm] & $35.2 \pm 4.2$ & $32.6 \pm 1.9$ & 0.08 \\
\hline AoGradMax [mm Hg] & $100.0 \pm 27.3$ & $97.6 \pm 22.8$ & 0.76 \\
\hline AoGradMean [mm Hg] & $62.1 \pm 16$ & $60.9 \pm 17$ & 0.96 \\
\hline AVA [cm $\left.{ }^{2}\right]$ & $0.66 \pm 0.08$ & $0.61 \pm 0.14$ & 0.31 \\
\hline EF $(\%)$ & $53.05 \pm 14.3$ & $57.2 \pm 13$ & 0.34
\end{tabular}

Data are presented as the number (\%) of patients or mean value $\pm S D$. AVA - aortic valve area, AoGradMax - maximum aortic gradient, AoGradMean - mean aortic gradient, EF - ejection fraction, IVS - interventricular septum, LVDD - left ventricular diastolic diameter, LVOT - left ventricular outflow tract, TTE - transthoracic echocardiography.

\section{B}

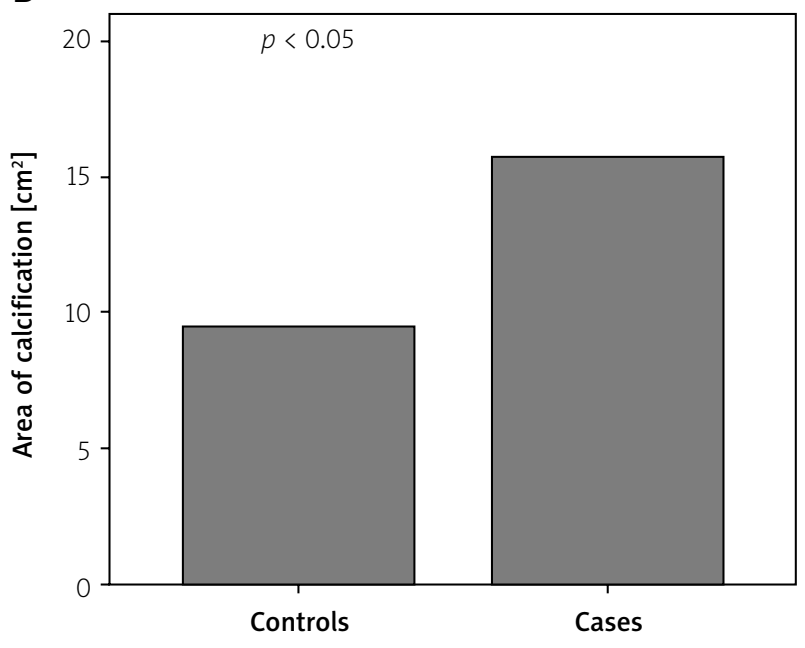

Figure 2. Aortic valve calcifications in cases and controls. A - Volume of calcifications, B - area of calcification, $\mathbf{C}$ - curvature of calcification 
Table III. Results of univariate modeling of variables predictive of paravalvular leak after TAVI

\begin{tabular}{lccc} 
Parameter & Odds ratio & 95\% Confidence interval & $P$-value \\
\hline Volume $\left[\mathrm{cm}^{3}\right]$ & 9.032 & $<1.658 ; 49.203>$ & 0.011 \\
\hline Area/magnitude $\left[\mathrm{cm}^{2}\right]$ & 1.227 & $<1.056 ; 1.425>$ & 0.008 \\
\hline Curvature of calcification $\left[\mathrm{cm}^{3}\right]$ & 5412.958 & $\langle 1.711 ; 17120823.307\rangle$ & 0.037 \\
\hline Aortic annulus $[\mathrm{mm}]$ & 1.833 & $<1.074 ; 3.130\rangle$ & 0.026
\end{tabular}

ysis of aortic valve calcifications is able to predict paravalvular leak following TAVI. Both the cases and controls had a CoreValve prosthesis implanted in the aortic position and their clinical characteristics were well matched and adjusted. The clinical characteristics of the patients did not differ from those described in other series of TAVI patients [16]. The only statistically significant difference noted was the size of the aortic annulus - which was larger in case patients than in control ones. Aortic root diameter (at the sinus of Valsalva) and left ventricular outflow tract (LVOT) diameter were insignificantly larger in cases than in controls. Because the association between the occurrence of paravalvular leak and aortic annulus was expected, we adjusted for this difference in multivariate analysis, in which it did not prove to be an independent predictor of paravalvular leak. It must be mentioned that the influence of aortic annulus on the risk of paravalvular leak may be compensated by the choice of the correct valve size and valve expansion (in the case of balloon-expandable prostheses), as other authors have previously stated in their studies. For example, Unbehaun et al. demonstrated in multivariate analysis that NYHA class IV, male sex, and absence of prior aortic valve surgery were responsible for the presence of paravalvular leak [17]. In our series we did not observe differences in the clinical characteristics between the study and control group. This may be explained by the case-control settings that we used and small sample size of our series. Until now, several attempts have been made to assess the relationship between calcifications of the aortic complex (assessed in the MSCT) and the presence of paravalvular leak. Haensig et al. evaluated 120 patients treated by TAVI using scoring analogous to the Agatston calcium scoring of coronary arteries (Aortic Valve Calcium Scoring (AVCS)) in MSCT. Paravalvular leak was assessed in echocardiography and angiography. Increasing AVCS was associated with a significantly higher risk of paravalvular leak [18]. Similarly, Ewe et al. described a set of 79 patients undergoing TAVI, qualitatively evaluating the volume of calcification in MSCT and its localization. A significant relationship between calcification characteristics and significant aortic regurgitation was reported [19]. In the analysis of 100 patients who received a CoreValve during TAVI, John et al. [10] demonstrated a significant correlation between the presence of atherosclerotic deposits of the aortic complex and the presence of paraval- vular leak. As in the above-mentioned article, Schultz et al. [20], Vahanian et al. [21] and Khalique et al. [22] described the relationship between the presence of atherosclerotic deposits and significant aortic valve regurgitation after TAVI. In contrast, Wood et al. [23] did not observe any correlation between the presence of leak after TAVI and the degree of calcification of the aortic valve, which was most likely related to the small group of patients included in the analysis $(n=26)$.

A new self-expandable valve was introduced recently to reduce the incidence of paravalvular leaks. It is equipped with an outer wrap intended to enhance contact between the valve and the native aortic annulus. Limited data presented recently at the American College of Cardiology Annual Scientific Session 2017 suggest its greater efficacy in limiting aortic periprosthetic leaks [24]. It has to be noted that in none of the above-mentioned articles were the calcifications fully evaluated for their amount and structure by semi-automated methods. The quantitative morphometric analysis of the calcification distribution in the aortic complex proposed here may be more objective than semiquantitative methods proposed so far, and help to isolate the different patterns of the distribution and severity of calcifications. This was a preliminary, hypothesis-generating study. Its continuation in a prospectively planned study, with derivation and validation series, may contribute to the development of prospectively validated semi-automatic methods for the quantitative assessment of calcifications of the aortic complex. The results of the study may influence the results of the engineering work on the new valve models as well as subsequent clinical trials improving the efficacy and safety of procedures, especially in high-risk groups.

The basic limitation of this project is the case-control design and small study and control group size. As mentioned above, however, it was a pilot study, aiming to assess the feasibility of the method before commencing a large prospective analysis.

\section{Conclusions}

Occurrence of paravalvular leak after TAVI is related to the size of calcification surface of the aortic complex. Quantitative assessment of aortic valve calcification volume, area and shape is feasible and yields clinically important information. 


\section{Conflict of interests}

The authors declare no conflict of interest.

\section{References}

1. Leon M, Mac M, Miller C, et al. Transcatheter aortic-valve implantation for aortic stenosis in patient who cannot undergo surgery, N Engl J Med 2010; 363: 1597-607.

2. Olasińska-Wiśniewska A, Grygier M, Lesiak M, et al. Przezcewnikowa implantacja zastawki aortalnej. Nowa szansa dla pacjentów wysokiego ryzyka ze stenozą aortalną. Folia Cardiol Excerpta 2011; 4: 227-35.

3. Bagienski M, Kleczynski P, Dziewierz A, et al. Early- and mid-term outcomes after transcatheter aortic valve implantation. Data from a single-center registry. Adv Interv Cardiol 2016; 12: 122-7.

4. Généreux P, Head S, Hahn R, et al. Paravalvular leak after transcatheter aortic valve replacement. The new Achilles' heel? A comprehensive review of the literature. J Am Coll Cardiol 2013; 61: 1125-36.

5. Lerakis S, Hayek SS, Douglas PS, et al. Paravalvular aortic leak after transcatheter aortic valve replacement: current knowledge. Circulation 2013; 127: 397-407.

6. Kleczyński P, Zasada W, Bagieński M, et al. Paravalvular leak after transcatheter aortic valve implantation (TAVI): short-term results. Data from Polish national POL-TAVI registry. Cardiol J 2016; 23: 163-8.

7. Barbanti M, Yang TH, Rodès CJ, et al. Anatomical and procedural features associated with aortic root rupture during balloon-expandable transcatheter aortic valve replacement. Circulation 2013; 128: 244-53.

8. Détaint D, Lepage L, Himbert D, et al. Determinants of significant paravalvular regurgitation after transcatheter aortic valve: implantation impact of device and annulus discongruence. JACC Cardiovasc Interv 2009; 2: 821-7.

9. Kleczyński P, Dziewierz A, Daniec $M$, et al. Impact of post-dilatation on the reduction of paravalvular leak and mortality after transcatheter aortic valve implantation. Kardiol Pol 2017; 75: 742-8.

10. John D, Buellesfeld L, Yuecel S, et al. Correlation of device landing zone calcification and acute procedural success in patients undergoing transcatheter aortic valve implantations with the self-expanding CoreValve prosthesis. JACC Cardiovasc Interv 2010; 3: 233-43.

11. Harbaoui B, Montoy M, Charles P, et al. Aorta calcification burden: towards an integrative predictor of cardiac outcome after transcatheter aortic valve implantation. Atherosclerosis 2016; 246: 161-8.

12. Koos R, Mahnken AH, Dohmen G, et al. Association of aortic valve calcification severity with the degree of aortic regurgitation after transcatheter aortic valve implantation. Int J Cardiol 2011; 150: 142-5.

13. Kosek M, Witkowski A, Dąbrowski M, et al. Transcatheter aortic valve implantation in patients with bicuspid aortic valve: a series of cases. Kardiol Pol 2015; 73: 627-36.

14. Kochman J, Huczek Z, Scisło P, et al. Comparison of one- and 12-month outcomes of transcatheter aortic valve replacement in patients with severely stenotic bicuspid versus tricuspid aortic valves (results from a multicenter registry). Am J Cardiol 2014; 114: 757-62.

15. Kappetein AP, Head SJ, Généreux P, et al. Updated standardized endpoint definitions for transcatheter aortic valve implantation: the Valve Academic Research Consortium-2 consensus document. Am J Cardiol 2012; 60: 1438-54.

16. Stokłosa P, Szymański P, Dąbrowski M, et al. The impact of transcatheter aortic valve implantation on left ventricular performance and wall thickness - single-centre experience. Postep Kardiol Interv 2015; 11: 37-43.

17. Unbehaun A, Pasic M, Dreysse S, et al. Transapical aortic valve implantation: incidence and predictors of paravalvular leakage and transvalvular regurgitation in a series of 358 patients. J Am Coll Cardiol 2012; 59: 211-21.

18. Haensig M, Lehmkuhl L, Rastan AJ, et al. Aortic valve calcium scoring is a predictor of significant paravalvular aortic insufficiency in transapical-aortic valve implantation. Eur J Cardiothorac Surg 2012; 41: 1234- 41.

19. Ewe SH, Ng AC, Schuijf JD, et al. Location and severity of aortic valve calcium and implications for aortic regurgitation after transcatheter aortic valve implantation. Am J Cardiol 2011; 108: 1470-7.

20. Schultz CJ, Tzikas A, Moelker A, et al. Correlates on MSCT of paravalvular aortic regurgitation after transcatheter aortic valve implantation using the Medtronic CoreValve prosthesis. JACC Cardiovasc Interv 2011; 78: 446-55.

21. Vahanian A, Alfieri O, Al-Attar N, et al. Transcatheter valve implantation for patients with aortic stenosis: a position statement from the European Association of Cardio-Thoracic Surgery (EACTS) and the European Society of Cardiology (ESC), in collaboration with the European Association of Percutaneous Cardiovascular Interventions (EAPCI). Eur Heart J 2008; 29: 1463-70.

22. Khalique OK, Hahn R, Gada H, et al. Quantity and location of aortic valve complex calcification predicts severity and location of paravalvular regurgitation and frequency of post-dilation after balloon-expandable transcatheter aortic valve replacement. JACC Cardiovasc Interv 2014; 7: 885-94.

23. Wood DA, Tops LF, Mayo JR, et al. Role of multislice computed tomography in transcatheter aortic valve replacement. Am J Cardiol 2009; 103: 1295-301.

24. Forrest JK. 30-day safety and echocardiographic outcomes following transcatheter aortic valve replacement with the self-expanding repositionable Evolut PRO system. Washington: American College of Cardiology Annual Scientific Session; 2017; 17-9. 